"The 'individually wrapped' square slices of cheese are iconic of a massproduced American consumer good. It is pre-packaged and ready-to-eat and caters specifically to the needs of an individual, as opposed to a group or family, on-the-go." 


\section{CANNED PEACHES AND CHICKEN PARTS Postmodern Food in Don DeLillo's White Noise}

NICOLE WONG

DESCRIPTIONS AND INTERACTIONS WITH FOOD SERVE AS SIGNIFIERS OF CULTURAL VALUES IN THE POSTMODERN SOCIETY OF DON DELILLO'S NOVEL WHITE NOISE. AMID A CONSTANT STREAM OF NAME BRAND ADVERTISEMENTS AND FLASHY TELEVISION COMMERCIALS, CHARACTERS STRUGGLE TO FIND SUBSTANTIVE MEANING IN THEIR LIVES. DELILLO PRESENTS A CONSUMER CULTURE SWAMPED IN EXCESS, BELONGINGS, AND COMMODITIES, WHERE FOOD ITEMS CHARACTERIZE THEIR BUYERS AND EVEN COMMIDIFY THEIR OUTLOOKS ON LIFE. FROM FAMILY BARGAIN PACKS OF POTATO CHIPS INDICATING SUCCESS AND WELL-BEING, TO PLASTIC-WRAPPED SLICES OF CHEESE FACILITATING AN EFFICIENT YET ISOLATED LIFE, THIS ESSAY DISCUSSES DELILLO'S DIFFERENT USES OF FOOD IMAGERY THROUGHOUT THE NOVEL. DELILLO'S PORTRAYAL OF A POSTMODERN CONSUMER SOCIETY IS PUT INTO DIALOGUE WITHACCLAIMED EXPERTS AND CRITICS JEAN BAUDRILLARD AND THORSTEIN VEBLEN, AS WELL AS ARTISTIC WORK THAT COMMENTS ON THE ROLE OF 'POP FOODS' IN CONTEMPORARY AMERICAN CULTURE, INCLUDING WORKS BY POP ARTISTS ANDY WARHOL AND ROY LICHTENSTEIN AND POET ALLEN GINSBERG. 
In Don DeLillo's White Noise, the commodification of daily life and the value placed on brand consumption are exemplified through DeLillo's usage of food in the novel. The postmodern world that DeLillo presents is driven by consumer needs, of which food is essential. As the novel progresses, DeLillo's characters have intriguing descriptions and interactions with food and garbage, which are markedly different before and after the Airborne Toxic Event-a chemical spill that forces the protagonist, Jack Gladney, and his family to briefly evacuate their home. This paper will investigate DeLillo's use of food as a signifier of cultural values and how it changes and differs throughout the novel, especially in relation to the Airborne Toxic Event. DeLillo's use of food will be placed within a larger cultural context, comparing it to contemporary works in art and poetry that address American consumer culture. This discussion will ultimately reveal DeLillo's broader message that the only dependable way to find meaning in life in a postmodern life is by instilling value into the seemingly empty images, whether in advertisements or on food packaging labels, that surround us.

Critics on the topic of consumerism in White Noise often bring up the ground-breaking writings of Jean Baudrillard and his portrayal of consumer society in order to demonstrate how DeLillo fits into the postmodern picture. Critic Leonard Wilcox assesses DeLillo's works, especially White Noise, as "a view of life in contemporary America that is uncannily similar to that depicted by Jean Baudrillard." Wilcox continues,

For White Noise especially - because it most specifically explores the realm of information and mediascapeBaudrillard's works provide an interesting, valuable, and even crucial perspective... In this world common to both Baudrillard and DeLillo, images, signs, and codes engulf objective reality; signs become more real than reality and stand in for the world they erase ... for both Baudrillard and DeLillo a media-saturated consciousness threatens the concept of meaning itself. $\mathrm{i}$
This issue of the indeterminable "objective reality" amid the "images, signs, and codes" is the crux of understanding DeLillo's postmodern consumer society. This commodity culture dictates the postmodern reality for the Gladney family. Jack Gladney's "branding” of the Hitler Studies Program, the declared "Family Nights" of simply watching television together in the same room, and frequent trips to the grocery store blend what is supposedly real with signifying actions into a portrayal of life that is marketable yet ultimately lacking in substance. Critic Elise A. Martucci argues that although DeLillo's world may be similar to how Baudrillard describes consumer society, "the novel is more than a simple fictionalization of postmodern theories. By comprising a mixture of the postmodern themes of representation, reflexive language, and subjectivity with the humor and humanity of a slice-of-life novel, White Noise effectively brings the reality and dangers of American consumer society into a starker and more powerful light." While it is true that DeLillo's novel is not just a "simple fictionalization" of Baudrillard's theories, to perhaps reduce Wilcox's argument as such, the "reality and dangers of American consumer society" are only brought into a "more powerful light" after the Airborne Toxic Event. As evidenced by the descriptions of food discussed below, the Airborne Toxic Event marks a change in the characters' relations with food, implying a change in their relations with the postmodern world. Martucci also argues that "Gladney is at times aware and at other times oblivious to the postmodern simulacra and the stimulation of his world."iii This distinction is vital since Gladney is able to act as both a subject and an analyst of the Baudrillardian world in which he lives. Postmodernism-that is, to be self-conscious, self-reflective, intensely theoretical, and re-contextualizing in the way in which we construct truth and meaning-inclusively applies to the characters in the novel, the depicted society, and the literary form itself.

On the first page of the novel, Jack Gladney describes the clamor of college students moving in to their dormitories, and among the list of material possessions ("small refrigerators and table ranges; the cartons of phonograph records 
and cassettes; the hairdryers and styling irons; the tennis rackets, soccer balls ... "), names "the junk food still in shopping bags-onion-and-garlic chips, nacho thins, peanut crème patties, Waffelos and Kabooms, fruit chews and toffee popcorn; the Dum-Dum pops, the Mystic mints." iv A few pages later, a similar run-down of snacks from the Gladney kitchen is given: "Wilder was still seated on the counter surrounded by open cartons, crumpled tinfoil, shiny bags of potato chips, bowls of pasty substances covered with plastic wrap, flip-top rings and twist ties, individually wrapped slices of orange cheese."v In the two earlier examples, the incessant listing of items and namebrand "Waffelos" and "Dum-Dum pops" are overwhelming in their sheer quantity and specificity. The thought of consuming "nacho thins" with "peanut crème patties", "pasty substances" and "orange cheese", is sickening and excessive with a disregard for flavor or content of the food item. The fact that it is all "junk food" also alludes to its dietary excess. There is neither steak nor vegetables, but instead all insubstantial 'empty' carbohydrates such as "toffee popcorn" and "potato chips." None of it would constitute a real meal, yet Wilder is surrounded by it all, and it is as necessary to college students as hairdryers and tennis rackets. The items are already used ("open cartons", "crumpled tinfoil") and everything else is soon to be consumed by way of the easily accessible "flip-top rings" or "twist ties". Consumer culture moves quickly and efficiently, and the food items are both a product of and catalyst for this consumerist lifestyle. The "individually wrapped" square slices of cheese are iconic of a mass-produced American consumer good. It is pre-packaged and ready-to-eat and caters specifically to the needs of an individual on-the-go. Efficiency is favored over the actual quality of the cheesewhich, with its familiar artifical "orange" color, is an inferior, less expensive standardized good. Yet this characteristically orange cheese is still the preferred choice of the Gladneys. In fact, this processed cheese is also called American cheese, implying its pervasiveness in American consumer culture, and is used in cheeseburgers and grilled-cheese sandwiches across the nation to this day.
The product listings of inventory exist both outside and inside the Gladney house, which suggests that this way of buying and eating is indicative of a social norm; it portrays the whole society as bogged down in excess, belongings, and commodities. The food-buying habits reveal the heavy influence of conspicuous consumption in a very literal way, that is, through a bodily consumption of food. Through food, DeLillo raises issues of life being insubstantial, fake, and inauthentic. People also seem to construct their realities and characterize themselves through these objects.

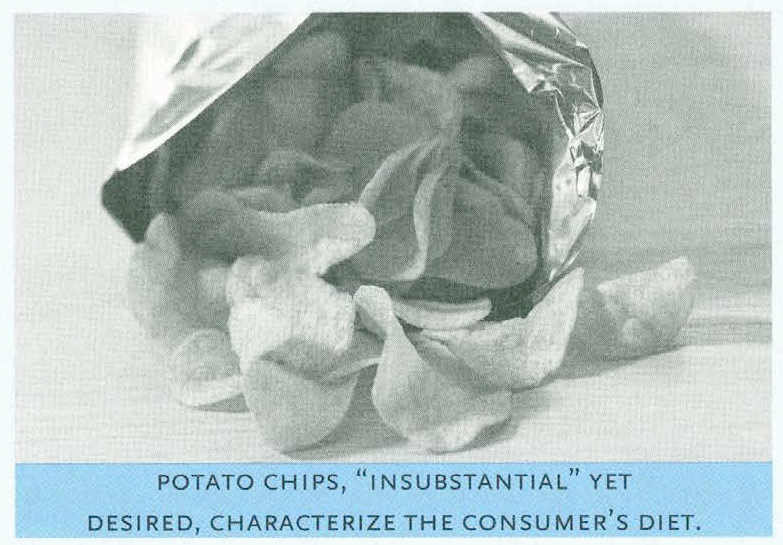

There appears to be little criticism explicitly addressing the usage of food in White Noise. Nevertheless, there is a literary forum surrounding the significance of certain 'pop' foods, such as those listed in the previous passages, in American contemporary culture. Sarah E. Newton writes in her essay "The Jell-O Syndrome" that "the study of popular commercial food products can have value... in uncovering the intimate, important, and sometimes symbolic relationships people develop between themselves, their world, and the foods they eat."vi In her study of Jell-O, Newton discusses how the jiggly food is regarded and shared by all types of Americans. She claims, "Jell-O is early associated in the American psyche with love, family, and nurturance. But not all cultural connections with Jell$\mathrm{O}$ are so innocent. A number of informants tie Jell-O with sex ... If Jell-O is, as it appears to be, a cultural signifier of 


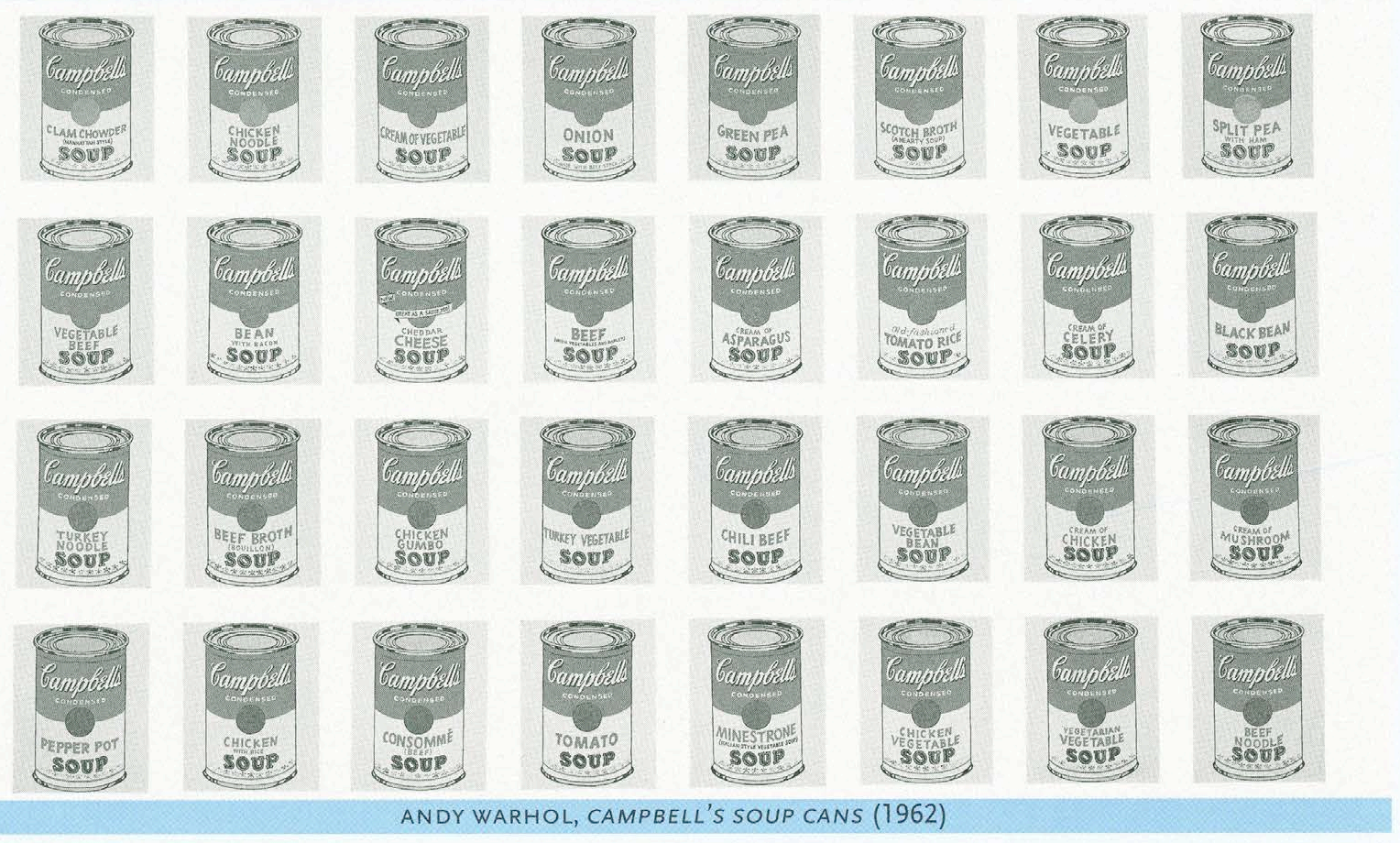

childhood innocence, of nourishment and comfort from the hands of moms and grandmas - of what is traditionally wholesome and pure-then stories of Jell-O adulteration [Jell-O made with vodka, Jell-O wrestling], are packed with meaning."vii Newton's arguments concerning the symbolism of Jell-O in society reinforces DeLillo's discussions of food as a cultural signifier.

A r99 exhibition at Bard College titled "Art What Thou Eat: Images of Food in American Art" also explored "the history of food in American society through its depiction by American artists of the nineteenth and twentieth centuries."viii The curators claimed that through a "close examination of art in a broader cultural context, a wealth of information can be revealed."ix The exhibition juxtaposed classic igth-century still life paintings of fruit with 20 thcentury representations of Wonderbread and geneticallyengineered fruit. Connections were also drawn between the traditional marketplace and the commercial supermarket and the transformation of sugar from a luxury good into

an American staple. The exhibition worked to "explore evolving artistic style and historical change using images of food as a vehicle." ${ }^{x}$ Similarly, by looking at the role of "food as a vehicle" in White Noise, it is possible to further our insight about postmodern reality.

In contrast to the earlier colorful descriptions of namebrand junk food, Jack also describes a chance encounter with a colleague who deals with food in a very different way:

We ran into Murray Jay Siskind at the supermarket. His basket held generic food and drink, nonbrand items in plain white packages with simple labeling. There was a white can labeled CANNED PEACHES. There was a white package of bacon without a plastic window for viewing a representative slice. A jar of roasted nuts had a white wrapper bearing the words IRREGULAR PEANUTS ... This is the new austerity,' he said. 'Flavorless packaging. It appeals to me. I feel I'm not only saving money but contributing to some 
kind of spiritual consensus. It's like World War III. Everything is white. They'll take bright colors away and use them in the war effort... I've bought these peanuts before. They're round, cubical, pockmarked, seamed. Broken... But they taste good. Most of all I like the packages themselves. You were right, Jack. This is the last avant-garde. Bold new forms. The power to shock. ${ }^{\mathrm{x}}$

The "whiteness" and "simplicity" of the packaging shocks regular consumers. Siskind's choice of generic food is unusual, even "avant-garde". The bacon without a "representative slice" showing from the outside implies suspicion of the enclosed contents, even though the representative slice is actually the real bacon inside. The packaging is "flavorless" and inferior for its mundane, monochromatic packaging. 'Normal' peanuts are supposedly all round and perfectly uniform, whereas the others are relegated to the less popular "irregular" jars. However, without the modern effects of technology and genetic engineering, peanuts are usually organically shaped and irregular, "round, cubical, pockmarked, seamed, broken”. In DeLillo's world, the natural peanuts are scrutinized and rejected, even though they all "taste good". Siskind likens buying the food to a war cause, as if to buy "white and simple" is to sacrifice something expected and desired, as if it is a self-inflicted inconvenience. The reference to a third World War also alludes to bare-bones war rations and the would-be assumption of simple packaging, which creates an interesting irony in recognizing the "bold new forms" of the white wrappers. The goods are simply what they say they are, yet the people of the novel distrust that.

The forms are neither "new" nor "bold"; in fact, the simple labels are the most primitive and straightforward form of advertising possible. The packaging lacks any commercial appeal. Siskind's food preferences are character-revealing when he says he is attracted to the "appealing ... new austerity" of it all. Siskind is an alternative buyer, and therefore an alternative thinker. $\mathrm{He}$ is a true postmodernist, by whom "the euphoric forms of electronic data and informational flow are to be enthusiastically embraced."xii People are uncomfortable with the blunt directness or lack of colorful distraction, as if they need the advertised packaging to validate what is inside. They need the "images and signs" on the outside to show them how they should feel about the food or what they will get out of it besides nourishment. Only Siskind, a postmodernist a step ahead of the average consumer, appreciates the nameless brands.

It also serves well to look at DeLillo's usage of food in the greater cultural context of Pop Art, which first emerged in America in the ig6os. In his extremely influential book, The Consumer Society, Jean Baudrillard discusses Pop Art:

Pop lays claim to be the art of the banal... but what is the banal but a metaphysical category, a modern version of the category of the sublime? The object is banal only in its use, in the moment of its use... The object ceases to be banal as soon as it signifies ... Now, we have seen that the 'truth' of the contemporary object is no longer to be used for something, but to signify, no longer to be manipulated as an instrument, but as a sign. And it is the success of pop, at its best, to show it to us as such. xiii

Pop Art depicted these "object" signifiers to question how we view consumer goods. Among many other famous series, Andy Warhol painted Campbell's Soup Cans, the subject of which is an everyday food object of mass consumption. Repeating the same image side-by-side, each one hanging on the wall as if shelved in a grocery store, the work alludes to the uniformity and ubiquity of the Campbell's can in society, and at the same time "implies not energetic competition [from advertisements] but a complacent abundance." xiv Warhol changed a banal food into the subject of a highly-regarded - and nowadays quite pricey-work of art. And now regarded as Pop Art, the image of the everyday can of soup (the "object") "ceases to be banal" and comes to signify something deeper about America's obsession with mass consumption and modern abundance of objects and possessions.

Other Pop artists, such as James Rosenquist and Roy 
Lichtenstein, also portrayed food in art in the commercial styles of billboards and comic strips. In Lichtenstein's painting Bananas \& Grapefruit \#1 (1972), he invokes the image of a bowl of fruit, the subject of many a classic still life, with abstract geometric shapes and solid planes of color, a highly-stylized depiction of fruit and a far cry from realistic resemblance. Lichtenstein's painting, however, seems to convey a similar message as DeLillo in implying a separation between natural organic foods and the artificial, almost too-perfect products of the new postmodern reality. In one of the various scenes in the grocery store in White Noise, Jack describes the fruit aisle, observing that "there were six kinds of apples, there were exotic melons in several pastels. Everything seemed to be in season, sprayed, burnished, bright."xv The description alludes to the strange plastic uniformity of the fruit. They are all "sprayed" with misty chemicals and preservatives and radiate eerily. The various types are lined up and ready-to-go, and all are "in season" - the fruit do not exist according to the rules of nature. Even the "exotic melons," which are rare or imported from afar, blend into the others. Again, the consumer is geared towards choosing only by the image value of the food, and not anything more substantial, like its taste or firmness.

As well as producing a consumer-driven and mass-produced atmosphere, DeLillo also uses food to signify family well-being and prosperity. On the way back from a supermarket trip, Jack reflects:

It seemed to me that Babette and I, in the mass and variety of our purchases, in the sheer plentitude those crowded bags suggested, the weight and size and number, the familiar package designs and vivid lettering, the giant sizes, the family bargain packs with Day-Glo sale stickers, in the sense of replenishment we felt, the sense of well-being, the security and contentment these products brought to some snug home in our souls - it seemed we had achieved a fullness of being that is not known to people who need less, expect less, who plan their lives around lonely walks in the evening.xvi
As in the previous citations from White Noise, the idea of excess and "plentitude" arises, with the rhythmic repetition of item after item. However, instead of the nauseating description of cheese puffs and chocolate, there is a different tone of plump "contentment" and "replenishment". Food represents comfort, success, and well-being. The marketed "family bargain packs" and "giant sizes" make Jack and Babette feel they have achieved more than others. The "crowded bags" imply a full house in size and number. The family, made up of a couple with kids from different marriages, can feel snug and secure knowing they not only have the means to eat, but that they are better off than the "lonely" who do not have the comforts or company of family, either. Jack and Babette feel they have more "fullness of being" than those who do not have their purchasing power or the need of buying in bulk. They have something-food, which represents prosperity and the ability to share it - that is not known to lonely individuals. The food is a physical reassurance and antidote to loneliness. Jack and Babette's desire not to be lonely seems to come second to satiating their physical hunger. Therefore, the food shopping not only nourishes their bodies, but reinforces how they view themselves as a family.

These points gel directly with the theories of consumer desires and conspicuous consumption by the famous sociologist and economist Thorstein Veblen. In his groundbreaking work, The Theory of the Leisure Class, Veblen theorizes that:

[t]he quasi-peaceable gentleman of leisure, then, not only consumes of the staff of life beyond the minimum required for subsistence and physical efficiency, but ... a specialization as regards the quality of the goods consumed... In the process of gradual amelioration which takes place in the articles of his consumption, the motive principle and the proximate aim of innovation is no doubt the higher efficiency of the improved and more elaborate products for personal comfort and well-being.xvii

Applying this to the previous paragraph, Jack Gladney, the 
"quasi-peaceable gentleman of leisure" shops for more than his "minimum required for subsistence", bringing home a "sheer plentitude" of "crowded bags", and relishes in the foodstuffs. Baudrillard also chimes into this discussion, arguing that consumer society is based on the eternal search for happiness, that:

the whole of the discourse on needs is based on a naive anthropology: that of the natural propensity to happiness. Happiness ... is the absolute reference of the consumer society: it is the strict equivalent of salvation . . Happiness has to be measurable. It has to be a well-being measurable in terms of objects and signs. xviii said. We heard sirens again, a different set this time, a larger sound... 'Why do you want dinner so early?' she said... 'I missed lunch. 'xix

In the face of impending danger, Jack wants to eat dinner. His need for normalcy and family come through in a time of emergency. He wants to eat dinner in an attempt to minimize the problem, to retreat to food as something familiar and stable. Jack wants to pretend as if everything is still fine, because as just discussed, dinner and food signify familial well-being and content. His request to eat dinner also reminds the reader that food is ultimately a grounding necessity for human existence. Whether or not the toxic cloud is growing or threatening, the family must still eat to

\section{"In the face of impending danger, Jack wants to eat dinner ... in an attempt to minimize the problem, to retreat to food as something familiar and known."}

To follow this logic, if buying food leads to comfort, and comfort leads to happiness, then food leads to happiness. Happiness, then, can be "measured" through food, so a sheer plentitude of food must signify a plentitude of happiness and well-being. It is possible that DeLillo had Veblen's theories in mind when he wrote this scene. Regardless, the Gladneys are able to put aside the natural disaster and their marital problems and construct their reality in these objects and signs. That is, until the occurrence of the Airborne Toxic Event.

Food also factors into life during the Airborne Toxic Event as a way to normalize the events that occur. When the Gladneys first hear about the mysterious toxic cloud, and are discussing it, Jack cuts off the dialogue:

'They're keeping it from getting bigger,' I said. 'When do we eat?' . . . '. . . if the billowing cloud is blown due south, it will miss us by a comfortable margin.' 'When do we eat?' I live. As Leon Kass writes in The Hungry Soul, "taking food is not a matter of choice. It is a desired necessity, indispensable for all vital activity and sought after by all living animals. Food is needed for growth and development, for maintenance and repair, for every motion and activity . . . One is only if and because one eats."xx With the threat of the toxic cloud, food now not only signifies the commodification and brand-consumption of postmodern culture, but carries a deeper indication about human sustenance and need.

In the beginning of Part III of the novel, after the Airborne Toxic Event has passed, DeLillo places the action immediately back in the supermarket, which gauges how society appears to have changed. Jack remarks:

Wilder sat inside [the shopping cart], on the collapsible shelf, trying to grab items whose shape and radiance excited his system of sensory analysis. There were two new develop- 
ments in the supermarket, a butcher's corner and a bakery, and the oven aroma of bread and cake combined with the sight of a bloodstained man pounding at strips of living veal was pretty exciting for us all. xxi

In the first sentence of this passage, the child's actions and sentiments are described in a mechanical and dehumanized way. His "system of sensory analysis" refers to his instinctual, infantile mind that "grabs items" off the shelf as any curious child does when excited. Using the phrase "system of sensory analysis" reduces Wilder to some sort of analytical machine or visual processor, which is what DeLillo is trying to imply about the postmodern nature of humans. The items "radiate", as if they are chemically enhanced, alive and beckoning, similar to the fruit in the store that were "sprayed, burnished, bright", yet the shelf itself is

"The mixture of the 'aroma of bread' and the 'sight of a bloodstained man' is ... 'pretty exciting' for the family. The "pounding at strips of living veal' is a violent death image, but the almost casual entertainment it brings the family is a strange and perverse indication of unresolved issues." only temporary and "collapsible", probably to accommodate the "new developments" in the store. The addition of the butchery and bakery also carries industrial tones of urban expansion and development. The phrase "new developments" could alternatively be interpreted as tumorlike growths, as if the entities just developed out of the supermarket, which itself is its own living, breathing thing. Traditional town trades of the butcher and baker have become commodified and imbibed into the supermarket conglomerate. It is an entire town in one location, catering to every consumer need at once. The mixture of the "aroma of bread" and the "sight of a bloodstained man" is strangely uncomfortable and unsettling to the reader, yet "pretty exciting" for the family. The "pounding at strips of living veal" is a violent death image, but the almost casual entertainment it brings the family is a strange and perverse indication of unresolved issues. The strangely mechanized description of the child and the "new developments" show progress - or is it really? - towards a more extreme postmodern tendency of the people and their surroundings.

This strangely social yet discomforting portrayal of the supermarket in White Noise also brings to mind Allen Ginsberg's famous poem "A Supermarket in California."xxii Both depict a postmodern supermarket of plastic "signs" and "images" ("In my hungry fatigue, and shopping for images, I went into the neon fruit supermarket"), and also deal with unexpected enthusiasm and awe for the supermarket's "radiance" ("What peaches and what penumbras!"; “the brilliant stacks of cans"). The supermarket is discussed on a social plane of human interaction ("Whole families shopping at night!", "Wives in the avocados, babies in the tomatoes!"), and is distinctly commercialized, apart from a more traditional reality ("Will we stroll dreaming of the lost America of love past blue automobiles in driveways, home to our silent cottage?"). Ginsberg's poem invokes similar feelings as does DeLillo's description of supermarkets: though they are highly-commercialized, almost fake, they are also somewhat of a haven and source of community, or at least the preserved and refrigerated remnants of it. David B. Clarke writes in his book, The 
Consumer Society and the Postmodern City, "modern social life was born of the city and its reconfiguration of social and physical space. The postmodern city amounts to its posthumous continuation, its fractal form. The postmodern city is 'less an identifiable city than a group of concepts-census tracts, special purpose bond-issue districts, shopping nuclei."'xxiii One of the concepts that make up the "postmodern city" would definitely be the supermarket, which in the text has just been "reconfigured". After the Airborne Toxic Event, their city is implicitly different, and food and supermarkets are just some of the "fractal forms" we can observe.

Now back to their 'normal lives', the Gladneys struggle to find unity and comfort in each other. One night they decide to go out for dinner, and so they:

all got in the car and went out to the commercial strip in the no man's land beyond the town boundary. The never-ending neon. I [Jack Gladney] pulled in at a place that specialized in chicken parts and brownies. We decided to eat in the car. The car was sufficient for our needs. We wanted to eat, not look around at other people. We wanted to fill our stomachs and get it over with. We didn't need light and space. ${ }^{\text {xxiv }}$

The "never-ending neon" again situates the family amid the neon lights from mass-produced, commercialized signs, which Jack acknowledges to be "never-ending", even in "no-man's land". The neon of consumerism is everywhere and unavoidable. Next, the fast food specialty of "chicken parts and brownies" is both unappealing in its reference to the disembodied bird as well as its subsequent mixture with something sweet and chocolate. The referral to "chicken parts" distances the clucking animal from the easily consumable pieces. Society has taken another step away from nature to convenience the needs of a consumer. Brownies are also individual sweet treats cut from a larger whole sheet, but one only thinks of this when juxtaposed against "chicken parts". In this passage, the Gladneys simply desire to "fill their stomachs" and be nourished; they are not looking for a social eating experience. They just want to "get it over with", not even looking for "light or space". The Gladneys acknowledge their bodily needs, but the warm familial feelings of well-being and content once felt from shopping, are now lost, or perhaps they realize that they were fake, just images, to begin with. The sentence structure in this passage addresses directly what they "want" and "need" - the short staccato of the sentences produce a strangely mechanized read.

Continuing the narration of this episode, Jack explains, "we ate fully dressed, in hats and heavy coats, without speaking, ripping into chicken parts with our hands and teeth ... I was surprised to find I was enormously hungry."xxv Here, the family has become strangely savage, messily "ripping into chicken parts" and not even bothering to take off their outerwear. As Jack eats, he realizes that he was unaware of how hungry he really was. Prior to eating, he had a basic bodily need that he virtually ignored. But once he starts eating, his animal instinct to satiate his body takes over. Something is not right here, whether it is a loss of humanity or an extremist take on postmodernism that causes the family to be out of touch with body experience. This is what the reader must ultimately grapple with.

In regards to the choice of the fast food restaurant, John Jakle, a University of Illinois cultural geographer, reasons that:

traditionally, roadside food has been prepared and consumed quickly and at relatively low prices. It has been attractive to people on the move in a society highly mobile geographically.... People find in roadside restaurants places of comfort where standardized environments, products, and services provide security as well as nourishment away from home. Anxiety from adventuring is contained by the familiar... xxvi

The roadside restaurant is iconic of consumer society. Jakle supposes the customers are road-tripping Americans, which makes it seem much stranger and jarring that a Gladney family dinner would take place in the parking lot 
of a fast food restaurant. Like the supermarket, fast food restaurants are places of comfort and security, and a sort of "nourishment away from home". For the Gladneys, in their desire to leave their home and their town if only for dinner, the fast food restaurant offers an alternative comfort, in which the "chicken parts" signify consumer society as they once knew it. After facing the "real danger" of the Airborne Toxic Event, they are lost in a changed landscape of consumerism.

A strange transition occurs, in which food characterizes the individuals themselves rather than their environment. Another example of food portrayed after the Airborne Toxic event is found in Heinrich's friend's eating habits. Jack explains:

I took Heinrich and his snake-handling buddy, Orest Mercator, out to the commercial strip for dinner. It was four in the afternoon, the time of day when Orest's training schedule called for his main meal. At his request we went to Vincent's Casa Mario ... We ordered pasta and water... I liked to watch Orest eat. He inhaled food according to aerodynamic principles. Pressure differences, intake velocities. He went at it silently and purposefully, loading up, centering himself, appearing to grow more self-important with each clump of starch that slid over his tongue. xxvii

Again, food is fuel-like for the character, and the mechanistic people act as its receptacle. Orest seems to exist only as an extreme model of postmodernity. His ridiculous desire to be in the Guinness Book of World Records for sitting in a glass tank filled with snakes dictates his eating schedule at four o'clock and strict diet of pasta and water. Jack describes "aerodynamic principles", "pressure differences", and "intake velocities" to characterize Orest's eating style with an appropriately 'aerodynamic' writing style. Pasta is reduced to "clumps of starch" because that is all they are to Orest, simply means of attaining his goal, of potentially fulfilling the "image" he has created for himself. Through Orest, we see yet another extreme example of a postmodern character.
It is also important to briefly examine DeLillo's use of garbage-or food waste-and its relation to postmodernism. Under the 'clean' surface of these citizens lies their waste. As Jack searches for Babette's Dylar pills-a blackmarket experimental drug supposed to cure the fear of death - he targets the kitchen trash compactor as a possible hideout for the pill. He describes:

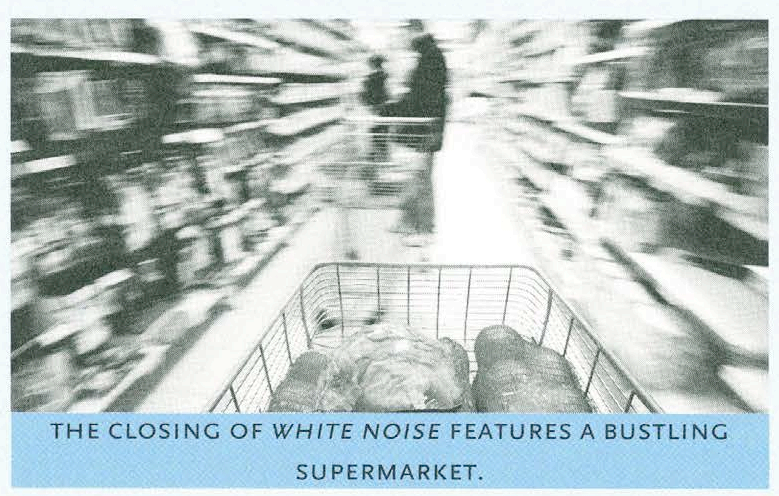

I took the bag out to the garage and emptied it. The compressed bulk sat there like an ironic modern sculpture, massive, squat, mocking. I jabbed at it ... then spread the material over the concrete floor. I picked through it item by item, mass by shapeless mass, wondering why I felt guilty, a violator of privacy .... Is garbage so private? Does it glow at the core with personal heat, with signs of one's deepest nature, clues to secret yearnings, humiliating flaws? What habits, fetishes, addictions, inclinations? ... I I found crayon drawings of a figure with full breasts and male genitals.... I found a banana skin with a tampon inside. Was this the dark underside of consumer consciousness? I came across a horrible clotted mass of hair, soap, ear swabs, crushed roaches, flip-flop rings, sterile pads smeared with pus and bacon fat, strands of frayed dental floss, fragments of ballpoint refills, toothpicks still displaying bit of impaled food.xxviii 
The mixture of Jack's perceptive yet unanswerable questions, which arise from picking apart the trash, are also discarded and left in the trash. Jack sifts through an odd and perverse assortment of trash, including the "shapeless masses" and the "flip-top rings" we saw at the beginning of the novel. The "glow" of food products before associated with the neon fruit and other radiating commercial products, now perhaps glow with something different. The "personal heat" alludes to the fact that all of these objects once belonged to someone, explaining Jack's issues with violating privacy. The uncomfortable mix of sex organs and kids' crayons, of fruit and tampons, and "impaled food", is sickening, a view of the "dark underside of consumer consciousness" - the side where the abundance of possessions rot and are quickly forgotten. In an article on waste and residue, Wutz states that:

cultural theorists and practitioners have paid attention to the status of trash within the changing frameworks of present-day cultures. British 'rubbish' sculptor Tony Cragg, for one, has observed that, in a climate of global consumerism, visual artists (arguably beginning with Duchamp) are finding 'values and meanings for all the population of objects in the world', including Coke bottles, Wendy's cups, and Campbell's cans ... xxix

The issue of finding meaning in everything, even what has already been discarded, brings us back again to the dependence on "images and signs" to find meaning in life. This quotation is also humorous when applied to DeLillo's passage because Jack compares his compacted square of trash to an "ironic modern sculpture", perhaps like that of Michel Duchamp or Tony Cragg. However, the construction of what is in the trash is DeLillo's artful construction! From its outermost frame looking into the text, the discarded debris is intentionally placed and described as if it were an "ironic modern sculpture".

White Noise concludes in a supermarket, describing an ultimate scene of confusion and postmodernity in consumer culture:
The supermarket shelves have been rearranged. It happened one day without warning. There is agitation and panic in the aisles, dismay in the faces of older shoppers. They walk in a fragmented trance, stop and go, clusters of well-dressed figures frozen in the aisles, trying to figure out the pattern, discern the underlying logic, trying to remember where they'd seen the Cream of Wheat... . The scouring pads are with the hand soap now, the condiments are scattered.... They turn into the wrong aisle, peer along the shelves, sometimes stop abruptly, causing other carts to run into them. Only the generic food is where it was, white packages plainly labeled.... There is a sense of wandering now, an aimless and haunted mood.... The men scan for stamped dates, the women for ingredients. Many have trouble making out the words. Smeared print, ghost images... and this is where we wait together, regardless of age, our carts stocked with brightly colored goods. A slowly moving line, satisfying .... Everything we need that is not food or love is here in the tabloid racks. $\mathrm{xxx}$

\section{"Food carries cultural} significance. . . food is used not only to ground characters as humans, but conversely to emulate the metaphoric 'consumption'
offood..."

Everything has been "rearranged", and the consumers do not know how to act accordingly. They look for familiar brands like "Cream of Wheat", and attempt to actually read 
the packaging instead of take them as "visual signifiers". Only Siskind's "generic food" remains where it was. Critic Marc Schuster interprets the end of the novel as a final comparison to life in the supermarket to just be a way of "keeping busy" before death "or, to borrow an apt colloquialism, 'check out'."xxxi They are not just "keeping busy", but the characters' interactions with food allow them and the reader to gain insight into their emotions and their understanding of the postmodern consumer society in which they exist. Food carries cultural significance, and in a search for how to find meaning in the hyper-reality of postmodernity, food is used not only to ground characters as humans, but conversely to emulate the metaphoric "consumption" of food as an acceptance of postmodern ideas and values. As Martucci argues, DeLillo shows us the "reality and dangers of American consumer society" in the dehumanization of the Gladneys after the Airborne Toxic Event. After the Event, food no longer holds the same significance, leading to a downfall and dehumanization of the characters. DeLillo shows us that, although it may be dangerous, the best way to find meaning in a postmodern society is by depending on the ostensibly empty "images, signs, and codes" of advertisements, television commercials, and food packaging.

\section{EN D NOTES}

i. Wilcox (346-347)

ii. Martucci (77)

iii. Ibid. (92)

iv. DeLillo (3)

v. Ibid. (7)

vi. Newton (266)

vii. Ibid. (257)

viii. Snyder-Grenier (1005)

ix. Ibid. (1006)

x. Ibid.

xi. DeLillo (18-19)

xii. Wilcox (350)

xiii. Baudrillard (II8)

xxiv. Publicity Publication excerpt, The Museum of Modern Art: New York (260)

xv. DeLillo (36)

xvi. Ibid. (20)

xvii. Veblen (73-74), Also: "The basis on which good repute in any highly organized industrial community ultimately rests is pecuniary strength; and the means of showing pecuniary strength, and so of gaining or retaining a good name, are leisure and a conspicuous consumption of goods" p. 84 . xviii. Baudrillard (49)

xix. DeLillo (III, II2)

xx. Kass (I9-29)

xxi. DeLillo (I59)

xxii. Ginsberg

xxiii. Clarke (94-95), within the quote reference is to: Pynchon,

The Crying of Lot 49, Vintage, London. I996

xxiv. DeLillo (220)

xxv. Ibid. (22I)

xxvi. Jakle (III, II4)

xxvii. DeLillo (252-253)

xxviii. Ibid. (247)

xxix. Wutz and Doctorow (503)

xxx. DeLillo (309-3IO)

xxxi. Schuster (9-IO), "As the novel draws to a conclusion, the relationship between death and shopping (the two major themes of White Noise) comes clearly into focus: shopping is what we do to keep ourselves busy until we die or, to borrow an apt colloquialism, "check out." From this perspective, the novel as a whole amounts to an extended examination of consumer culture's efforts at organizing society in a way that proffers the ritual of shopping as a means of holding death at bay even as we move inexorably toward it."

\section{REFERENCES}

Baudrillard, Jean. I970. The Consumer Society: Myths and Structures. London: Sage Publications.

Clarke, David B. 2003. The Consumer Society and the Postmodern City. New York: Routledge.

DeLillo, Don. 1985. White Noise. New York: Penguin Books.

Ginsberg, Allen. 1956. Howl and Other Poems. San Francisco: City Lights Books.

Jakle, John A. I995. "Roadside Restaurants and Place-ProductPackaging" in Fast Food, Stock Cars, and Rock ' $n$ ' Roll: Place and Space in American Pop Culture. George O. Carney, editor. Lanham: Rowman \& Littlefield Publishers.

Kass, Leon R. 1953. The Hungry Soul: Eating and the Perfecting of Our Nature. New York: The University of Chicago Press.

Martucci, Elise A. 2007. The Environmental Unconscious in the Fiction of Don DeLillo. New York: Routledge.

The Museum of Modern Art. Revised 2004, originally published 1999. Publicity Publication excerpt. MoMA Highlights. New York: The Museum of Modern Art. 
Newton, Sarah E. July-October 1992. "The Jell-O Syndrome: Investigating Popular Culture/Foodways" in Western Folklore, Vol. 51, No. 3,4. Western States Folklore Society.

Schuster, Marc. 2008. Don DeLillo, Jean Baudrillard, and the Consumer Conundrum. New York: Cambria Press.

Snyder-Grenier, Ellen M. December I99I. "Review: Art What Thou Eat: Images of Food in American Art." The Journal of American History, Vol. 78, No. 3. Organization of American Historians.

Veblen, Thorstein. I899. The Theory of the Leisure Class. New York: Sentry Press.

Wilcox, Leonard. Autumn I99I. "Baudrillard, DeLillo's White Noise, and the End of the Heroic Narrative." Contemporary Literature, Vol. 32, No. 3. University of Wisconsin Press.

Wutz, Michael and E.L Doctorow. Autumn, 2003. "Literary Narrative and Information Culture: Garbage, Waste, and Residue in the Work of E.L. Doctorow." Contemporary Literature, Vol. 44, No. 3. University of Wisconsin Press 